\title{
Tipicidad e imputación objetiva: su trascendencia para la labor del Ministerio Público y del Poder Judicial en el marco del Nuevo Código Procesal Penal \\ Carlos A. Pinedo Sandoval* http://dx.doi.org/10.21503/lex.v10i9.370
}

* Profesor de Derecho Penal y Teoría del Derecho en la Universidad de Piura. Presidente Fundador del Instituto de Ciencias Penales del norte del Perú.

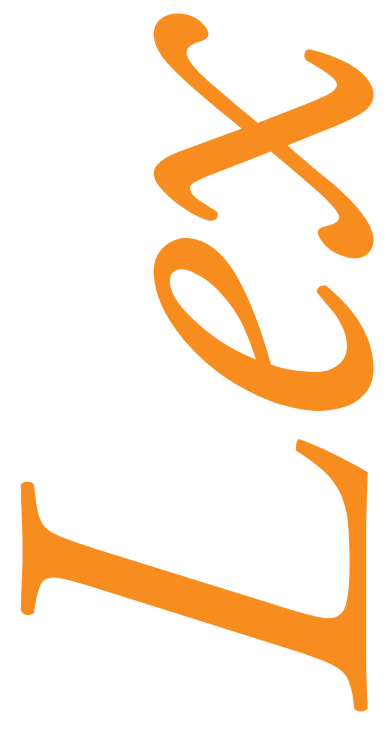





\section{INTRODUCCIÓN}

La doctrina nacional ha reconocido la enorme importancia de la labor de tipicidad. Así, se señala que "la tipicidad (...) constituye (...) una categoría del delito esencialmente garantista, pues vincula la determinación de la conducta delictiva y de la pena con el principio de legalidad", ${ }^{1} \mathrm{y}$ en este sentido, "(...) se convierte en el punto de inicio del examen judicial de un caso concreto; y al mismo tiempo, nos ofrece la garantía de la seguridad jurídica". Asimismo, a raíz de la reciente reforma procesal penal que se viene suscitando en nuestro país mediante la progresiva implementación de un sistema acusatorio-adversarial, la trascendencia de la que goza el juicio de tipicidad en la labor fiscal y judicial se ha hecho más evidente. Dicho juicio no debe reducirse a una mera labor de constatación de relaciones causales; por el contrario, el juicio de tipicidad debe entenderse estrictamente como un juicio de imputación. $\mathrm{Al}$ respecto, actualmente, la doctrina nacional es unánime en considerar insuficiente y no ajustada a la realidad aquella concepción del tipo penal objetivo-descriptivo-avalorativo.

Mediante el presente trabajo llegaremos a la conclusión de que la teoría de la imputación objetiva propuesta por Günther Jakobs -a diferencia de las otras alternativas- goza de mayor aptitud para arribar a soluciones justas, coherentes y con mayor eficacia en la práctica, por cuanto se enmarca dentro de un verdadero sistema del Derecho Penal, normativo y funcional, acorde con los rasgos de la actual dinámica social, estructurándose a partir de institutos dogmáticos que responden a la realidad: el riesgo permitido, el principio de confianza, la prohibición de regreso y la competencia de la víctima. Tal cometido resulta importante en

1 García Cavero, Lecciones de Derecho Penal, PG, p. 305: “(...) la tipicidad no solo permite delimitar la conducta permitida de la prohibida, sino también diferenciar las distintas formas de conducta prohibida en orden a sus consecuencias jurídicas (...)”. De modo similar, Bramont-Arias Torres, Luis M., Manual de Derecho Penal, PG, p. 128: "La tipicidad es una exigencia del Estado de Derecho, vinculada al principio de legalidad".

2 Villavicencio Terreros, Derecho Penal. PG, 1ra. ed. (3ra reimp.), p. 297. De modo similar, Peña Cabrera Freyre, Derecho Penal, PG, t. I, 3ra. ed., p. 350: “(...) la tipicidad es el primer filtro de valoración dogmática que debe someter a la conducta enjuiciada, a fin de determinar si esta constituye o no en realidad un verdadero injusto penal, pues esta atribución no se agota de ningún modo en este primer escalón categorial”. 
tanto se trata de una de las tendencias dogmáticas que progresivamente se encuentra ganando terreno tanto en la doctrina como en la jurisprudencia nacional, rescatándose su coherencia y racionalidad sistemática para la delimitación de los ámbitos de competencia, en el contexto de una sociedad cada vez más compleja. Asimismo, y aludiendo a lo señalado en los párrafos precedentes, en tanto herramienta dogmático-conceptual, dicha teoría se encuentra no solo a disposición del Ministerio Público y de la Defensa, sino también del Juez Penal, en tanto a este le corresponderá custodiar la vigencia de los principios, garantías y derechos que corresponden al imputado dentro del proceso. ${ }^{3}$

\section{LA TIPICIDAD: DE LA “CONSTATACIÓN” A LA IMPUTACIÓN}

Una primera -y a la vez elemental- acepción jurídica del término tipicidad es aquella que la define como un límite al ius puniendi, esto es, como "expresión genérica constitutiva del primer elemento dogmático del concepto de delito, que contiene las características generales que han de concurrir en una conducta para que se origine la intervención penal". "A este respecto, el Derecho Penal contemporáneo debe a Ernst von Beling (1866-1932) no solo el haberla configurado y dotado de contenido dogmático, elevándola al rango de categoría esencial del delito y concepto troncal de todo el sistema penal, sino que, además, le es tributaria de todas las consecuencias sistemáticas, dogmáticas y político-criminales ${ }^{5}$ que a partir de 1906, con la publicación de Die Lehre vom Verbrechen, se han desarrollado hasta el día de hoy. ${ }^{6}$ En este sentido, adquiere gran importancia, principalmente, el cambio de paradigma que el aporte de Beling significó respecto a la labor del juez, quien en un primer momento podía imponer una pena en razón de cualquier acción que a su juicio fuera antijurídica ${ }^{7}-$ situación duramente criticada por el liberalismo del siglo XVIII-, labor que, a partir de las bases conceptuales belingnianas respecto al tipo y a la tipicidad, encontraría el rumbo para adquirir progresivamente la entidad propia de una actividad interpretativa y limitadora.

En palabras de Beling, "puede concebirse la parte especial del Derecho Penal como una especie de catálogo en el cual las figuras de delito se encuentran alineadas [como] en

3 Este es el sentido, por ejemplo, de lo estipulado en el art. 3o del NCPP: "El Ministerio Público comunicará al Juez de la Investigación Preparatoria su decisión formal de continuar con las investigaciones preparatorias”.

4 De la Cuesta Aguado, Tipicidad e imputación objetiva, p. 62.

5 Respecto a estas tres consecuencias, vid. Roxin, Derecho Penal, PG, t. I., \$10, núm. 1-3.

6 Vid. Jakobs, Derecho Penal, PG, p. 189 y ss, quien resalta el hecho de que el concepto de tipo formulado antes de Beling no presenta gran utilidad, por lo que solo a comienzos del siglo XX "se activa dogmáticamente el concepto, al situarlo Beling como escalón independiente del delito, anterior a la antijuricidad y a la culpabilidad (Lehre vom Verbrechen, 1906) (...). Así pues, si bien el concepto de Beling no es consecuente, sí que es viable su intento de establecer, junto a la acción, aún antes del injusto, un escalón más del delito, y meritoria la articulación del delito que aporta, como acción típica, antijurídica y culpable. Esto, de todos modos, es discutido hasta en la actualidad".

7 Cfr. López Barja de Quiroga, Derecho Penal, PG, p. 56: "De ahí que posteriormente se consiguiera que únicamente ciertas conductas antijurídicas pudieran ser susceptibles de pena”. 
un libro de imágenes en el cual el "matar a un hombre", el "apoderamiento de una cosa mueble ajena”, etc., están esquemática y estilizadamente representados. (...) La tarea del jurista, naturalmente, es la de entender y manejar bien las imágenes". ${ }^{8}$ Para ello, explica el maestro alemán, "el jurista, en primer lugar, ha de hojear el catálogo de las clases de delito (las autónomas figuras delictivas) para establecer cuál de ellas está en consideración con respecto a la acción de que se trata. Entonces ya tiene, por decirlo así, el gancho al cual cuelga el caso. (...) Esta investigación es de primer plano porque todas las demás investigaciones dependen de esa comprobación"?

Si bien en Beling la tipicidad se plantea aún en una dimensión incipiente, dado el concepto de tipo penal objetivo, descriptivo y valorativamente neutro del que parte el maestro alemán, dicha categoría, sin embargo, permitirá a la actividad judicial adquirir mayor trascendencia respecto a la del legislador. En este orden de ideas, mientras que el legislador se encarga de construir, mediante leyes, el catálogo en el cual se comprenderán las distintas figuras delictivas, será el juez quien en cada caso concreto determine si una persona ha incurrido en el supuesto de hecho contemplado en el tipo penal. A ello se le conoce como labor de tipicidad o de "adecuación al catálogo", ${ }^{10}$ y, no obstante el aporte de Beling, se sitúa en el marco del sistema causalista del delito, donde la actividad judicial de tipicidad se reducía a una mera labor de constatación de la existencia de procesos causales; con ello, sin embargo, ya se había dado un paso fundamental. En dicho contexto, la afirmación hecha por Engisch (1899-1990) de que el acto de interpretar las normas jurídicas consiste en un "ir y venir de la mirada judicial desde las normas a los hechos y desde los hechos a las normas", ${ }^{11}$ no hace más que poner de relieve lo anterior.

Por otra parte, la evolución dogmática del contenido del tipo penal traería aparejada un cambio significativo respecto al modo de entender la labor de tipicidad. Así, gracias al paulatino proceso de normativización de las instituciones jurídico-penales, la tipicidad iría adquiriendo rasgos propios de una labor de imputación. Es precisamente en este sentido que, en el marco de un sistema penal funcional-normativista, la afirmación de que un hecho constituye un ilícito (entendido este como negación de una expectativa normativa institucionalizada) requiere la comprobación de que el hecho importa, en primer término, la infracción de una norma y, en segundo lugar, la verificación de que esta infracción no está autorizada (v. gr. que exista alguna causa de justificación o una situación de inexigibilidad). ${ }^{12}$ La primera operación

\footnotetext{
8 Beling, Esquema de Derecho Penal. La doctrina del delito tipo, p. 279 y ss.

9 Ibidem, p. 295 y ss.

10 Ibidem, p. 73.

11 Las referencias en Vigo, DOXA, № 21 (1998), vol. II, p. 495.

12 Cfr. Bacigalupo Zapater, Derecho Penal, PG, p. 211.
} 
resulta ser materia propia de la tipicidad, es decir, de la coincidencia del hecho cometido con la descripción abstracta, que es presupuesto de la pena, contenida en la ley.

\section{LA PROPUESTA DE GÜNTHER JAKOBS: LA IMPUTACIÓN OBJETIVA}

\section{La responsabilidad basada en la competencia}

A diferencia de la dogmática tradicional, que recurre a la causalidad, a la evitabilidad o al dolo para la atribución de un determinado suceso a su autor, Jakobs desarrolla un concepto estrictamente normativo. Para él, el juicio de imputación se fundamenta en la delimitación de ámbitos de competencia. En este sentido, primero hay que determinar si el sujeto tenía una posición de garante, si era competente para desplegar los deberes de seguridad en el tráfico o de protección frente a determinados bienes jurídicos con respecto a ciertos riesgos, para luego determinar si el suceso era evitable y cognoscible. ${ }^{13}$ Para la delimitación de ámbitos de competencia, hay que precisar, en primer lugar, cuál es la posición de garantía que tiene el sujeto (si esta se origina en una administración deficiente de su ámbito de organización, o en la transgresión de un vínculo institucional) y cuáles son los deberes que surgen de ella. En segundo lugar, y establecido el requisito anterior, se debe proceder a concretar el juicio de imputación con base en cuatro instituciones: el riesgo permitido, el principio de confianza, las acciones a propio riesgo (competencia de la víctima) y la prohibición de regreso. Demostrada la creación de un riesgo, en tercer lugar, se requiere, además, una realización del riesgo. Es decir, "que el mismo riesgo creado por el sujeto sea el que se concrete en la producción del resultado. Criterios como el fin de protección de la norma, la elevación del riesgo y el comportamiento doloso o gravemente imprudente de la víctima o un tercero sirven para saber cuándo se trata de la misma relación de riesgo y no de otra con distinto origen, no atribuible a quien ha creado inicialmente el peligro desaprobado". ${ }^{14}$

\section{2. Ámbitos de aplicación de la imputación objetiva}

En un sistema penal unitario como el defendido por Jakobs, la teoría de la imputación objetiva, como delimitadora del injusto del comportamiento, es aplicable a todos los tipos

13 Cfr. Montealegre Lynett/Perdomo Torres, en Los desafios del Derecho Penal en el siglo XXI. LH al Profesor Dr. Günther Jakobs, Yacobucci (Dir.), p. 63 y ss: "Ejemplo: un desprevenido transeúnte encuentra súbitamente en la calle a un herido en grave peligro (situación de peligro generante del deber) y no le presta ayuda (no realización de la acción esperada); posteriormente este fallece por falta de una oportuna intervención médica que el peatón tenía posibilidad de facilitarle trasladándolo a un hospital cercano (capacidad individual de acción). La muerte no le es imputable al transeúnte a pesar de la evitabilidad y el conocimiento. En efecto, si no tiene una posición de garante, porque él no ha creado el riesgo para los bienes jurídicos, ni tampoco tiene una obligación institucional de donde surja un deber concreto de evitar el resultado mediante una acción de salvamento, el resultado no le es atribuible. Responde solo por la omisión de socorro, y el fundamento de esa responsabilidad es quebrantar el deber de solidaridad que tiene todo ciudadano".

14 Ibidem, p. 64. 
de la Parte Especial, es decir, tanto a los delitos de resultado como a los de peligro, por igual a los ilícitos dolosos e imprudentes, así como a las acciones y omisiones; ${ }^{15}$ por otra parte, la imputación objetiva pretende ser aplicable también a los delitos consumados como a los tentados, puesto que para saber si una conducta es reprochable penalmente a título de tentativa, es indispensable que con ella se haya creado un riesgo jurídicamente desaprobado, el cual posteriormente resulte concretado en el resultado, ${ }^{16}$ entendido este no como una mera consecuencia naturalística, sino como una lesión a las reglas de la vida de relación social (quebrantamiento de la validez de las normas), de manera que, tanto en los delitos consumados como en las tentativas, debe existir un resultado jurídico-penal, pues de lo contrario el comportamiento no podrá ser reprochado.

En el sentido expresado anteriormente, Yesid Reyes ${ }^{17}$ agrega que el pretender reducir dicha teoría a una mera "imputación objetiva del resultado" no implica más que prolongar la inútil polémica sobre a cuál de los desvalores (de acción o de resultado) se debe otorgar preeminencia, y, además, se estaría desconociendo que, en sus orígenes, la imputación objetiva no fue simplemente un mecanismo para atribuir resultados, sino que fue bosquejada por Hegel como un instrumento para determinar cuándo una conducta podía ser considerada como la obra de alguien. Dicho con sus propias palabras: "Un abandono de la teoría final del injusto y la adopción de un nuevo sistema penal como el que aquí defendemos, supone entender la imputación objetiva como una teoría que reemplaza lo que tradicionalmente ha sido denominado el concepto jurídico penal de acción, por lo que en manera alguna puede ser solo referida a un resultado, sino a toda la actuación como obra de determinada persona". ${ }^{18}$

En resumen, cuál debe ser el campo de aplicación de la imputación objetiva en el Derecho Penal, depende ante todo del concepto mismo que se tenga de dicha teoría, de manera que mientras para algunos solo podrá ser referida a concretas modalidades delictivas, para otros tendrá un mayor ámbito de cobertura; siendo este último el caso de Jakobs, quien postula una versión amplia de la imputación objetiva.

$15 \mathrm{Al}$ respecto, vid. Jakobs, El fundamento del Sistema Jurídico Penal, p. 155 y ss: "Tanto respecto de la acción como de la omisión, se trata de la misma competencia por organización o del mismo 'fundamento jurídico especial'. Esto es, en definitiva, de la misma institución irrenunciable; por ello, se debe afirmar una completa congruencia de la responsabilidad por acción con la de la omisión".

${ }^{16}$ Cfr. Reyes Alvarado, Imputación objetiva, p. 84 y ss.

17 Cfr. Ibidem, p. 75 y ss.

18 Ibídem, p. 75 y ss; más adelante, p. 81, señala que "la generalizada tendencia de referir la imputación objetiva solo a los delitos de resultado es la lógica consecuencia de la estrecha interpretación que considera a esta teoría como un mecanismo exclusivamente apto para atribuir resultados; pero si de acuerdo con lo ya expuesto se entiende correctamente a la imputación objetiva como la teoría que permite establecer lo que para el Derecho Penal es una conducta lesiva de los intereses sociales, es decir, como el núcleo de la acción penalmente relevante, de la cual forma parte no solo un resultado sino, además, el imprescindible aspecto de la creación de un riesgo jurídicamente desaprobado, resulta innegable que la imputación objetiva no debe quedar reducida a los denominados delitos de lesión, y mucho menos a unos determinados tipos de resultado como los homicidios y las lesiones". 


\section{Institutos de la imputación objetiva}

\section{A. El riesgo permitido}

Por lo general, en las sociedades actuales, no forma parte del rol de cualquier ciudadano el eliminar cualquier riesgo de lesión de otro, lo cual significa que existe un riesgo permitido. ${ }^{19}$ Es decir, cuando las leyes determinan cómo ha de construirse un automóvil o un avión para que sea seguro en el tráfico, o cuándo cabe identificar lo que es un buen estándar de comportamiento médico, ello significa al mismo tiempo que el riesgo residual que siempre subsiste está permitido, al menos en el caso normal. Y es que la sociedad no es un mecanismo cuyo único fin sea la protección máxima de bienes jurídicos, sino que está destinada a hacer posibles las interacciones. Por tanto, la prohibición de cualquier puesta en peligro, de toda índole, imposibilitaría la realización de todo comportamiento social, incluyendo, por lo demás, también los comportamientos de salvación. ${ }^{20}$

\section{B. El principio de confianza}

Cuando el comportamiento de los seres humanos queda entrelazado, no forma parte del rol del ciudadano controlar permanentemente a todos los demás; de otro modo, no podría haber reparto del trabajo. En consecuencia, existe un principio de confianza, no cabiendo imaginar una sociedad sin este punto de partida. ${ }^{21}$ Por poner un ejemplo: unos contactos sociales tan fugaces como los que se dan entre los participantes en el tráfico viario solo se pueden organizar si se protege la confianza en que cada uno solo responde de su conducta defectuosa y no de la posible conducta defectuosa de otro. ${ }^{22}$ Esta interpretación no es del todo novedosa. La idea de que en un mundo en que los contactos interpersonales se suceden continuamente es imprescindible poder confiar en que el resto se comportará conforme al estándar del cuidado debido, ya la enunció Stratenwerth a principios de los años sesenta del siglo pasado. ${ }^{23}$ Sin embargo, en la concepción de Jakobs, esta confianza no emana de la responsabilidad ajena sino, principalmente, de la diferenciación de roles que se ha verificado en la sociedad. ${ }^{24}$

19 En este punto coincidimos con Piña Rochefort, Rol social y sistema de imputación, p. 353, para quien "preguntarse por el riesgo permitido no es sino preguntarse por el rol mismo. ¿Cuáles son los riesgos que X puede generar manteniéndose dentro de lo permitido? La respuesta no puede formularse sin atender al valor "X". Solo considerando dicho valor es posible determinar cuál es la función y ver luego si existe o no una defraudación a dicha función".

${ }^{20}$ Cfr. Jakobs, La imputación objetiva, p. 26.

${ }^{21}$ Cfr. Jakobs, La imputación objetiva, p. 28 y ss.

${ }^{22}$ Jakobs, Sociedad, norma y persona, p. 54.

${ }^{23}$ La referencia es de Piña Rochefort, Rol social y sistema de imputación, p. 377 y ss.

${ }^{24}$ Cfr. Ibidem, p. 377 y ss. 


\section{La prohibición de regreso}

La prohibición de regreso es una aportación particular de Jakobs a la objetivización del tipo, la misma que ha generado todo un interesante campo de discusión para la ciencia del Derecho Penal. ${ }^{25}$ Según esta categoría, el carácter conjunto de un comportamiento no puede imponerse de modo unilateral-arbitrario. En este sentido, quien asume un vínculo estereotipado-inocuo con otro ser humano no quebranta su rol como ciudadano, aunque el otro incluya el vínculo en una organización no permitida. Por consiguiente, existe una prohibición de regreso, con el contenido de que un comportamiento estereotipadamente inocuo no constituye participación en una organización no permitida. ${ }^{26} \mathrm{~A}$ modo de ejemplo, y en el marco de una economía con una intensa división del trabajo, se presupone que no forma parte del rol del vendedor de un producto estándar el cuidar de que el comprador no lo utilice de forma delictiva o de cualquier otra forma lesiva. ${ }^{27} \mathrm{Jakobs}^{28}$ distingue, así, entre división del trabajo separadora y división del trabajo vinculante. Lo primero se refiere a la prohibición de regreso, mientras que lo segundo implica la vinculación de la aportación previa con la continuación delictiva ulterior (intervención delictiva).

\section{La competencia de la víctima}

Pueden presentarse casos en los cuales la configuración de un contacto social competa no solo al autor, sino también a la víctima, y ello incluso en un doble sentido: puede que su comportamiento fundamente que se le impute la consecuencia lesiva a ella misma, y puede que se encuentre en la desgraciada situación de estar en la posición de víctima por obra del destino, por infortunio. Existe, por tanto, sostiene Jakobs, una competencia de la víctima. ${ }^{29}$ $\mathrm{Al}$ respecto, del mismo modo que para delimitar el ámbito de responsabilidad del autor, ha de partirse no de un suceso psíquico sino de algo normativo, del quebrantamiento del rol, también en el lado de la víctima lo decisivo está en determinar si la víctima ha desempeñado el rol de una víctima o, precisamente, el rol de alguien que configura la situación, es decir, de quien actúa a riesgo propio.

\section{EL JUICIO DE TIPICIDAD (IMPUTACIÓN OBJETIVA) EN LA LABOR FISCAL Y JUDICIAL}

En el Perú, el TC ha reconocido que "(...) al juez penal le corresponde efectuar el juicio de tipicidad, que no es otra cosa mas que la valoración que se hace con miras a determinar si

25 Cfr. Feijoo Sánchez, Imputación objetiva, p. 160.

26 Cfr. Jakobs, La imputación objetiva, p. 29.

27 Jakobs, Sociedad, norma y persona, p. 54.

28 Jakobs, Lectio doctoralis. p. 42 y ss.

29 Jakobs, La imputación objetiva, p. 32 y ss; también Hruschka, RPDJP, 2 (2001), p. 181 y ss. 
la conducta objeto de examen coincide o no con la descripción típica contenida en la ley. Es una operación mental (proceso de adecuación valorativa conducta-tipo) llevada a cabo por el intérprete (juez) mediante la cual se constata o verifica la concordancia entre el comportamiento estudiado y la descripción típica consignada en el texto legal. La norma típica debe ser vigente, valida formal y materialmente.."30. Al respecto, si bien no negamos que -como afirma el TC- "(...) es el juez el llamado a ser el "señor" del juicio de tipicidad", ${ }^{31}$ consideramos que a partir de la reciente reforma procesal penal llevada a cabo en nuestro país, la labor de tipicidad es una labor que aquel comparte en iguales condiciones con el Ministerio Público, actuando este en su calidad de director de la investigación, por un lado, y defensor de la legalidad, ${ }^{32}$ por otro. Observando la realidad de nuestro sistema penal, podemos, entonces, darnos cuenta de que la labor de tipicidad se erige como una exigencia y una garantía que se encuentra presente a lo largo de todas las etapas del proceso y que deviene en labor fundamental en tanto que informa y da sentido a la ratio de todos los actos procesales, esto es, determinar si el imputado es competente por la infracción de la expectativa normativa institucionalizada y, por ende, si resulta responsable penalmente.

La afirmación anterior se ve reforzada si tomamos en consideración que, por un lado, la Constitución Política, en el lit. "d". inc. 24 de su art. $2^{\circ}$-al consagrar el principio de legalidad ${ }^{33}$ como una garantía para salvaguardar la libertad y seguridad personales- estipula que "Nadie será procesado ni condenado por acto u omisión que al tiempo de cometerse no esté previamente calificado en la ley, de manera expresa e inequívoca, como infracción punible; ni sancionado con pena no prevista en la ley", ${ }^{34}$ y, por otro -en el marco del sistema acusatorio que inspira nuestra actual reforma procesal penal-, al prescribir el art. IV del TTPP del NCPP que "El Ministerio Público es el titular del ejercicio de la acción penal en los delitos y tiene la carga de la prueba. Asume la conducción de la investigación desde su inicio", ${ }^{35}$ resulta claro que la labor del Ministerio Público recibe también un mensaje directo del Principio de Legalidad en mención. En este orden de ideas, podemos señalar que, desde que el Fiscal Provincial toma conocimiento de la notitia criminis y procede a iniciar

30 STC. Exp. N. ${ }^{\circ} 00031-2009-\mathrm{PHC} / \mathrm{TC}$ (Ayacucho), Fund. $\$ 11$. (Énfasis en el original).

31 STC. Exp. N. ${ }^{\circ} 00031-2009-\mathrm{PHC} / \mathrm{TC}$ (Ayacucho), Fund. $\$ 11$. (Énfasis en el original).

32 En contra de dicha caracterización, Madroñero Sobrino, en Dogmática y ley penal. LH a Enrique Bacigalupo, López Barja de Quiroga/Zugaldía Espinar (coord.), p. 1373 y ss.

33 Ampliamente sobre esta cuestión, Roxin, Derecho Penal, PG, $\$ 5$, n.m. 1-11; en específico sobre los cuatro aspectos que edifican el Principio de Legalidad, Mir Puig, Derecho Penal, PG, p. 515 y ss.

34 Siguiendo esta directriz, el CP peruano establece en el art. II de su TTPP que "Nadie será sancionado por un acto no previsto como delito o falta por la ley vigente al momento de su comisión, ni sometido a pena o medida de seguridad que no se encuentren establecidas en ella», y en el art. 11 ${ }^{\circ}$, que "Son delitos y faltas las acciones u omisiones dolosas o culposas penadas por la ley".

35 También el art. $11^{\circ}$ del Dec. Leg. No 052 (LOMP) prescribe que "El Ministerio Público es el titular de la acción penal (...)". 
la acción penal -y al dirigirse esta a determinar si en realidad se trata de un hecho ilícito-, tanto en las diligencias preliminares como en la Investigación Preparatoria propiamente dicha, la actividad del representante del Ministerio Público girará en torno a la necesidad de establecer dos cuestiones esenciales: la quaesito facti y la quaesito iuris. La primera está referida a la verificación de la realidad de un suceso. Probados los hechos, la segunda cuestión será determinar si quien intervino en el suceso, como su causante, debe responder por ello. Para esta tarea, resultará necesario, fundamentalmente, llevar a cabo un juicio de tipicidad, a través del cual se estará dando vigencia al Principio de Legalidad ${ }^{36}$.

La labor de tipicidad que corresponde al Ministerio Público tiene su máxima expresión en lo señalado por el lit. "f" del inciso 1 del art. 349 NCPP, donde se establece que "La acusación fiscal será debidamente motivada y contendrá: (...) f) el artículo de la ley penal que tipifique el hecho, así como la cuantía de la pena que se solicite; (...)”. Por consiguiente, una incorrecta o deficiente labor de subsunción por parte del Ministerio Público produciría nada menos que una injusticia para el imputado, o, en otro caso, una injusticia para la víctima, lo cual sucedería, por ejemplo, si después de realizar las diligencias preliminares, el Fiscal indebidamente dispone el archivo de lo actuado por considerar, sin un buen fundamento dogmático, que el hecho denunciado no constituye delito o no es justiciable penalmente; ${ }^{37} \mathrm{o}$ si, con base en el literal b. del inciso 2 del art. $344^{\circ}$ del NCPP, ${ }^{38}$ el Fiscal sobresee indebidamente la causa por considerar erróneamente que el hecho imputado no es típico. ${ }^{39}$ En todo caso, y a partir de la disposición fiscal de formalización de la investigación, ${ }^{40}$ tanto al juez de la investigación preparatoria como, posteriormente, al Juzgado a cargo del juicio oral o, en su caso, a la Sala Penal de Apelaciones, les corresponde garantizar los derechos fundamentales de las partes intervinientes en el proceso, por lo que, ya sea bien sobre la base de una adecuada o

36 Sobre la estrecha vinculación entre tipicidad y legalidad, vid., Roxin, Derecho Penal, PG, $\$ 7$, n.m. 5; en este sentido, también, Abanto Vásquez ("A manera de presentación: nociones preliminares”), en Roxin, La imputación objetiva en Derecho Penal, p. 14.

37 Art. 334º.1 NCPP: "Si el Fiscal al calificar la denuncia o después de haber realizado o dispuesto realizar diligencias preliminares, considera que el hecho denunciado no constituye delito o no es justiciable penalmente (...), declarará que no procede formalizar y continuar con la Investigación Preparatoria , así como ordenará el archivo de lo actuado”.

38 Art. 344‥2 NCPP: "El sobreseimiento procede cuando: (...) b) El hecho imputado no es típico o concurre alguna causa de justificación, de inculpabilidad o de no punibilidad”.

39 Por esa razón se ha previsto como herramienta procesal a favor del denunciante la llamada Queja de Derecho ante el Fiscal Superior Penal de Apelaciones, regulada en el Art. 334․ 5 NCPP: "El denunciante que no estuviese conforme con la disposición de archivar las actuaciones o de reservar provisionalmente la investigación, requerirá al Fiscal, en el plazo de cinco días, eleve las actuaciones al Fiscal Superior". Por su parte, en lo que respecta al sobreseimiento, el Art. 345.2 NCPP señala: "Los sujetos procesales podrán formular oposición a la solicitud de archivo dentro del plazo establecido. La oposición, bajo sanción de inadmisibilidad, será fundamentada y podrá solicitar la realización de actos de investigación adicionales, indicando su objeto y los medios de investigación que considere procedentes".

40 El Art. 339․2 NCPPP establece que como efecto de la formalización de la investigación, que "(...) el Fiscal perderá la facultad de archivar la investigación sin intervención judicial". 
de una incorrecta labor de tipicidad a cargo de la fiscalía, cuentan, entre otras, con la facultad -dentro de la audiencia preliminar de control de acusación y ante una labor de subsunción débil o incorrecta- de disponer la devolución de la acusación y la suspensión de la audiencia por cinco días para que se corrija el defecto; ${ }^{41} \mathrm{o}$, en último caso $-\mathrm{y}$ después de la etapa de juzgamiento-, de absolver o condenar al imputado (art. 398 ${ }^{\circ}$ y $\left.399^{\circ} \mathrm{NCPP}\right) .^{42}$

\section{REFLEXIONES FINALES}

Imputar o no a una persona un determinado suceso como obra suya dependerá, en muchos casos, de la posición dogmática que el operador de justicia penal adopte, lo cual implica conocer el intenso debate que se ha llevado a cabo al respecto desde la otrora formulación del tipo objetivo-descriptivo belingniano. En este marco, y en torno a la tendencia hacia la normativización de las instituciones jurídico-penales, en la discusión dogmática actual ha venido ganando terreno el sistema dogmático desarrollado por el profesor Günther Jakobs, cuya médula fundamental es su teoría de la imputación objetiva, herramienta dogmática que se encuentra a disposición de los operadores de justicia para determinar quién o quiénes son los competentes por la realización de un suceso típico: el autor, la propia víctima, un tercero, $\mathrm{o}$, sin que nadie sea competente, interpretar el suceso como un infortunio. Ahora bien, y no obstante resultar cierto que el asumir determinada posición respecto a una teoría puede llevar al operador de justicia penal a resolver un determinado caso de modo distinto de si hubiera asumido una opuesta, en lo que concierne a las distintas versiones de la imputación objetiva, ${ }^{43}$ sin embargo, cabe mencionar que todas ellas tienen un núcleo en común, el cual radica en la utilidad que persiguen. Así por ejemplo, en el prólogo a su Imputación objetiva, empieza diciendo Jakobs ${ }^{44}$ que el objeto de esta teoría es la averiguación y la fijación del significado social de un determinado comportamiento. Es decir, se trata de delimitar el comportamiento socialmente adecuado y el comportamiento socialmente inadecuado. Sobre el contenido de dicha teoría, resulta posible distinguir, a efectos didácticos, dos niveles: por un lado, la

41 Art. 352․2 NCPP: "Si los defectos de la acusación requieren un nuevo análisis del Ministerio Público, el Juez dispondrá la devolución de la acusación y suspenderá la audiencia por cinco días para que se corrija el defecto, luego de lo cual se reanudará".

42 La transcendencia de la labor de tipicidad en el proceso penal se manifiesta también en la denominada "tesis desvinculatoria", recogida en el art. $744^{\circ} \mathrm{NCPP}$, según la cual el Juez Penal tiene la posibilidad de corregir la incorrecta o deficiente labor de subsunción efectuada por el Ministerio Público. Así, se señala en el inciso primero que "Si en el curso del juicio, antes de la culminación de la actividad probatoria, el Juez Penal observa la posibilidad de una calificación jurídica de los hechos objeto del debate que no ha sido considerada por el Ministerio Público, deberá advertir al Fiscal y al imputado sobre esa posibilidad. Las partes se pronunciarán expresamente sobre la tesis planteada por el Juez Penal y, en su caso, propondrán la prueba necesaria que corresponda. Si alguna de las partes anuncia que no está preparada para pronunciarse sobre ella, el Juez Penal suspenderá el juicio hasta por cinco días, para dar oportunidad a que exponga lo conveniente”.

43 Una interesante exposición de las distintas versiones de la imputación objetiva en, Abanto Vásquez, en XVI Congreso Latinoamericano, VIII Iberoamericano y I Nacional de Derecho Penal y Criminología, p. 7 y ss.

44 Cfr. Jakobs, La imputación objetiva en Derecho Penal, p. 10. 
calificación del comportamiento como típico (imputación objetiva del comportamiento), y, por otro, la determinación -en el ámbito de los delitos de resultado- de que el resultado producido queda explicado precisamente por el comportamiento objetivamente imputable (imputación objetiva del resultado). ${ }^{45}$

La imputación jurídico-penal del hecho, con base en criterios estrictamente normativos, desembocará en una nueva manera de entender el juicio de tipicidad. Así, el operador de justicia, en un primer nivel, determinará la llamada imputación objetiva del comportamiento y-de ser el caso- del resultado. Afirmada la imputación objetiva, tendrá lugar el segundo nivel de imputación constituido por la llamada imputación subjetiva. ${ }^{46}$ Ahora bien, de acuerdo con lo que hemos venido afirmando hasta aquí, y en tanto que, por una parte, el juicio de tipicidad implica llevar a cabo interpretación judicial, y, por otra, al encontrarse informada la tipicidad del principio de legalidad, podemos afirmar que, en consecuencia, el juicio de tipicidad implica realizar interpretación constitucional. La cuestión que subyace es, en el fondo, cómo resolver con justicia un problema, en este caso, el problema de si se debe atribuir carácter delictuoso a un suceso y de si es posible atribuirlo a una persona como obra suya. En este sentido, consideramos que la teoría de la imputación objetiva del profesor Günther Jakobs aporta las condiciones para arribar a soluciones más justas.

45 Peñaranda Ramos et al., en Estudios de Derecho Penal, p. 57.

46 García Cavero, Derecho Penal Económico, PG, p. 339: "Finalmente, el operador de justicia procederá a determinar si no hay estructuras relevantes que lleven al descargo de la imputación y, por tanto, nieguen la imputación jurídico-penal del hecho afirmada previamente de modo general". 


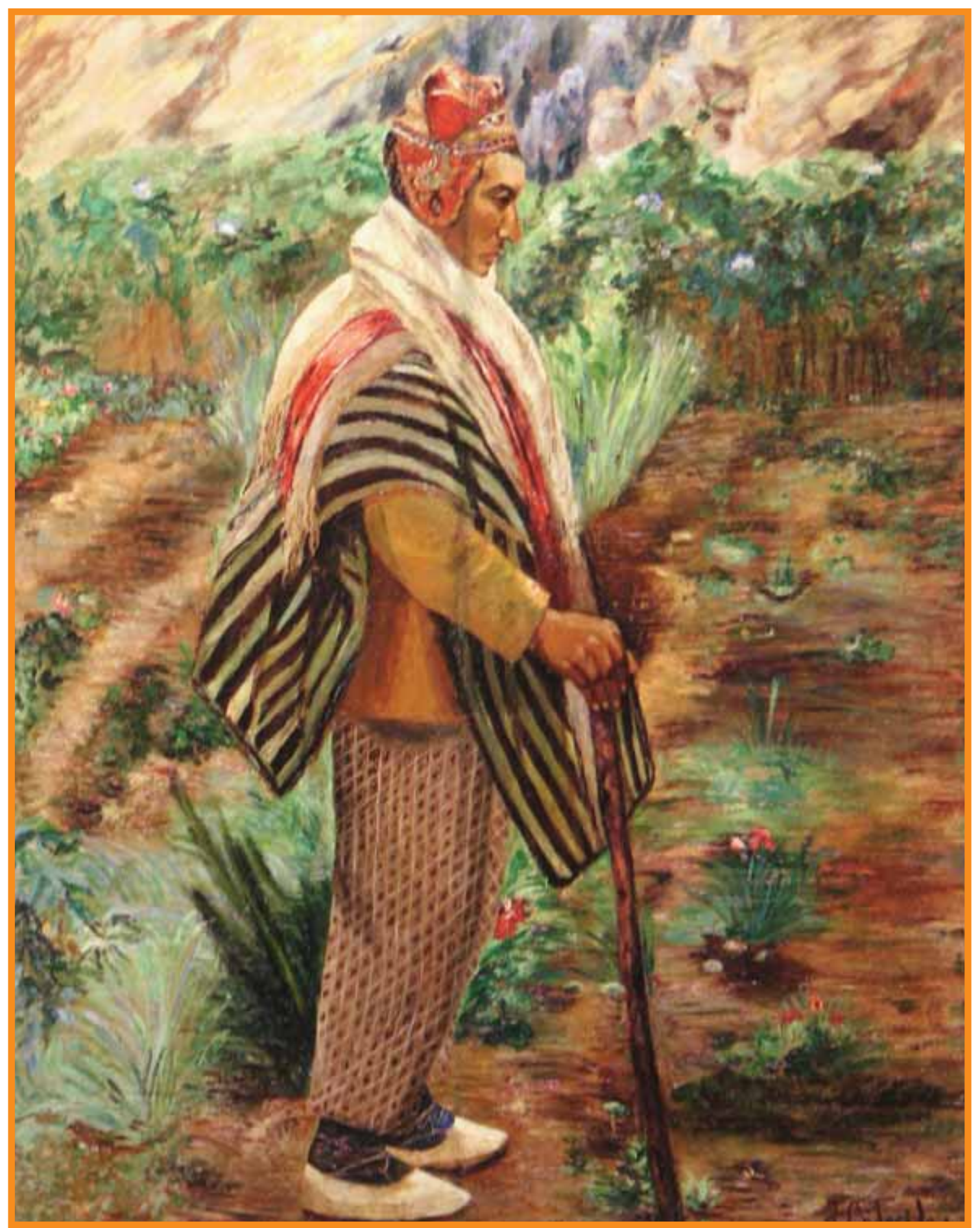

El alcalde. Colección BBVA Banco Continental. 